\title{
Off-pump transapical implantation of artificial chordae to correct mitral regurgitation: Early results of a single-center experience
}

\author{
Kestutis Rucinskas, MD, ${ }^{a}$ Vilius Janusauskas, MD, ${ }^{a}$ Diana Zakarkaite, MD, ${ }^{\text {a }}$ Sigita Aidietiene, MD, ${ }^{\mathrm{a}}$ \\ Robertas Samalavicius, MD, ${ }^{\mathrm{b}}$ Giovani Speziali, MD, ${ }^{\mathrm{c}}$ and Audrius Aidietis, $\mathrm{MD}^{\mathrm{a}}$
}

\begin{abstract}
Objectives: This study evaluated the safety and efficiency of the NeoChord DS1000 system (NeoChord, Inc, Minneapolis, Minn), a device designed to deliver artificial chordae tendineae (neochords) in a beating heart with minimally invasive techniques through left anterolateral minithoracotomy.
\end{abstract}

\begin{abstract}
Methods: Thirteen patients with severe mitral regurgitation and isolated posterior mitral valve leaflet prolapsed underwent operation with the NeoChord DS1000 system. Mitral valve dimensions were anteroposterior $34 \mathrm{~mm}$ $(29-45 \mathrm{~mm})$ and mediolateral $40 \mathrm{~mm}(29-58 \mathrm{~mm})$. All patients had an ejection fraction greater than $55 \%$. With a beating heart, through a left anterolateral thoracotomy, under transesophageal echocardiographic guidance, the NeoChord DS1000 was introduced into the left ventricle 2 to $4 \mathrm{~cm}$ posterolateral from the apex. The prolapsed leaflet was grasped with the device, and expanded polytetrafluoroethylene suture deployed and attached to the posterior leaflet. Six patients received 2 sutures, 4 received 3 sutures, and 2 received 4 sutures. All patients reached 6 months' follow-up and underwent transthoracic echocardiography to evaluate mitral regurgitation.
\end{abstract}

Results: Median operative duration was 113 minutes (80-150 minutes). Less than second-degree mitral regurgitation in 6 months was achieved in 11 patients $(85 \%)$. One patient $(8 \%)$ had recurrent mitral regurgitation in 1 month, and another had conversion to conventional mitral valve repair because of leaflet damage with the device. There were no further serious procedure-related complications.

Conclusions: Beating-heart transapical neochord implantation was feasible, could be performed safely, and resulted in a relatively short procedure time. Larger studies and longer follow-up are needed to validate these promising results. (J Thorac Cardiovasc Surg 2014;147:95-9)

Techniques for mitral valve repair have undergone continual evolution during the past 50 years. ${ }^{1}$ Simple posterior leaflet prolapse is associated with very high mitral repair rates in many centers. ${ }^{2,3}$ The overall repair rate of $69 \%$ observed in the Society of Thoracic Surgeons database $^{4}$ represents a progressive increase through an 8 -year period but remains significantly lower than is achievable. Acute mitral repair rates are now approximating $98 \%$ for all common mitral disease etiologies in referral centers, ${ }^{1}$ even when applied to all comers. ${ }^{5}$ The lower overall Society of Thoracic Surgeons rate is at least partially explained by

\footnotetext{
From the Department of Cardiovascular Medicine, ${ }^{\mathrm{a}}$ Vilnius University, Vilnius, Lithuania; the Centre of Anaesthesia, Intensive Care, and Pain Management, ${ }^{b}$ Department of Intensive Care, Vilnius University, Vilnius, Lithuania; and the Department of Cardiothoracic Surgery, ${ }^{\mathrm{c}}$ University of Pittsburgh Physicians, Pittsburgh, $\mathrm{Pa}$.

Disclosures: G.S has a financial interest in and works as proctor for NeoChord Inc. All other authors have nothing to disclose with regard to commercial support.

Read at the 93rd Annual Meeting of The American Association for Thoracic Surgery, Minneapolis, Minnesota, May 4-8, 2013.

Received for publication April 28, 2013; revisions received July 21, 2013; accepted for publication Aug 1, 2013; available ahead of print Oct 7, 2013.

Address for reprints: Vilius Janusauskas, MD, Department of Cardiovascular Medicine, Vilnius University, Santariskiu St 2, Vilnius, 08661, Lithuania (E-mail: janvilius@yahoo.com; vilius.janusauskas@santa.lt).

$0022-5223 / \$ 36.00$

Copyright (C) 2014 by The American Association for Thoracic Surgery

http://dx.doi.org/10.1016/j.jtcvs.2013.08.012
}

more complex scenarios (including anterior or bileaflet involvement, lesion complexity, and patient comorbidities) and less experience on the part of many surgeons relative to those at reference centers.

Cumulative evidence obtained worldwide shows that early surgery should be the preferred management approach. ${ }^{6}$ Specifically, mitral repair should be performed

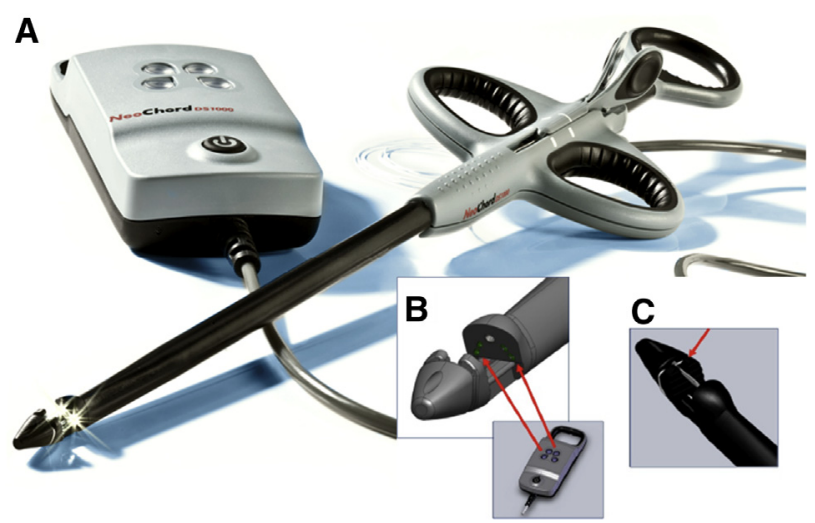

FIGURE 1. NeoChord device. A, The NeoChord DS1000 consists of the hand-held delivery instrument and a tethered Leaflet Verification Display. B, As the device apex grasps the leaflet, the Leaflet Verification Display gives information on leaflet grasping quality. $\mathrm{C}$, The device deploys a suture $4 \mathrm{~mm}$ from the leading edge of the target leaflet. 


\section{Abbreviations and Acronyms \\ $\mathrm{LV}=$ left ventricle \\ $\mathrm{MR}=$ mitral regurgitation \\ TACT $=$ Transapical Artificial Chordae Tendineae [trial] \\ TEE $=$ transesophageal echocardiography}

before New York Heart Association functional class III to IV symptoms develop. ${ }^{7,8}$ NeoChord (NeoChord, Inc, Minneapolis, Minn) has developed a new surgical tool for less invasive off-pump, beating-heart mitral valve repair. The NeoChord DS1000 system (Figure 1) is designed to deliver artificial chordae tendineae, or neochords, under beating-heart conditions with transesophageal echocardiography used (TEE) to guide the device to the target leaflet for deployment of the neochords. The multicenter, nonrandomized, prospective Transapical Artificial Chordae Tendineae (TACT) trial (clinicaltrials.gov ID: NCT01777815) for evaluation of the NeoChord DS1000 system safety and feasibility is ongoing. In this article, we report our first experience with this device.

\section{MATERIALS AND METHODS Patient Selection}

The local bioethics committee has approved this prospective study, and every patient provided individual consented to undergo the procedure. From December 2011 to August 2012, 13 patients (5 male and 8 female) underwent mitral valve repair with the DS1000 system at Vilnius University Hospital Santariskiu Klinikos, Vilnius, Lithuania. Median patient age was 60 years, with a range from 33 to 73 years. Median body mass index was $27 \mathrm{~kg} / \mathrm{m}^{2}$, with a range from 20 to $34 \mathrm{~kg} / \mathrm{m}^{2}$. All patients had good function of the left ventricle (LV), with an ejection fraction greater than $55 \%$. Per the protocol, all patients had severe mitral regurgitation (MR, grade 3 or 4 ) with isolated posterior leaflet prolapse. All patients were candidates for conventional mitral valve surgery. Most patients had symptoms of severe MR contributing to early-stage progression of heart failure, and all patients were under medical treatment. Patients with functional or ischemic MR, severe LV dysfunction, anterior or bileaflet prolapse, or permanent atrial fibrillation were excluded from this study. Baseline patient characteristics are presented in Table 1 . These patients were at low surgical risk with an average euroSCORE II of $1.06 \%(0.56 \%-1.59 \%)$. With our preoperative TEE assessment, we targeted patients exhibiting wide prolapsing segments and patients in which clinically significant coaptation depth $(6-12 \mathrm{~mm})$ could be restored.

\section{Patient Screening}

All patients underwent preoperative transthoracic echocardioscopy, and most of the patients had 3-dimensional TEE to determine suitability for transapical neochord implantation. Preoperative baseline echocardiograms were used to determine the optimal planned number of neochords to be deployed and their target location on the posterior leaflet. In general, deployment of more than 2 neochords is desired for each patient to balance the load per neochord. Preoperative examination of the width of the prolapsing segment or location of clefts in the leaflet tissue guided the target sites for the planned neochords.

\section{DS1000 Device}

As shown in Figure 1, The NeoChord DS1000 consists of the handheld delivery instrument and a tethered Leaflet Verification Display with 4 fiberoptic lumens enabling confirmation of leaflet capture. Through a limited left lateral thoracotomy in a beating heart, the device transapically accesses the mitral valve, grasps the flailing leaflet, and deploys a suture as an artificial chord ( $4 \mathrm{~mm}$ from the leading edge of the target leaflet). Fiber optics gives information of leaflet-grasping quality. If a leaflet is grasped with the full depth of the device jaws, the Leaflet Verification Display will show 4

TABLE 1. Baseline characteristics, intraoperative data, and postoperative results

\begin{tabular}{|c|c|c|c|c|c|c|c|c|c|c|c|}
\hline \multirow[b]{3}{*}{ Patient } & \multicolumn{11}{|c|}{ Baseline } \\
\hline & \multirow[b]{2}{*}{ Age (y) } & \multirow[b]{2}{*}{ Sex } & \multirow{2}{*}{$\begin{array}{c}\text { Height } \\
(\mathrm{cm})\end{array}$} & \multirow{2}{*}{$\begin{array}{c}\text { Weight } \\
(\mathbf{k g})\end{array}$} & \multirow[b]{2}{*}{ NYHA } & \multirow[b]{2}{*}{ LVEF (\%) } & \multicolumn{2}{|c|}{$\begin{array}{c}\text { MV annulus } \\
\text { distance (mm) }\end{array}$} & \multicolumn{2}{|c|}{ MV leaflet (mm) } & \multirow{2}{*}{$\begin{array}{r}\text { MR } \\
\text { grad }\end{array}$} \\
\hline & & & & & & & AP & ML & Anterior & Posterior & \\
\hline 1 & 65 & $\mathrm{~F}$ & 162 & 75 & II & 55 & 26 & 33 & 15 & 13 & 3 \\
\hline 2 & 61 & M & 176 & 92 & II & 55 & 32 & 44 & 21 & 17 & 3 \\
\hline 3 & 69 & $\mathrm{~F}$ & 156 & 60 & III & 55 & 32 & 33 & 21 & 18 & 3 \\
\hline 4 & 73 & $\mathrm{~F}$ & 155 & 65 & II & 55 & 30 & 37 & 20 & 11 & 3 \\
\hline 5 & 63 & M & 178 & 93 & II & 55 & 30 & 29 & 17 & 14 & 3 \\
\hline 6 & 49 & M & 186 & 97 & II & 55 & 35 & 28 & 20 & 11 & 3 \\
\hline 7 & 38 & M & 185 & 87 & II & 55 & 45 & 57 & 27 & 22 & 3 \\
\hline 8 & 62 & $\mathrm{~F}$ & 170 & 98 & II & 55 & & & & & 3 \\
\hline 9 & 72 & $\mathrm{~F}$ & 167 & 75 & III & 55 & 29 & 35 & 17 & 20 & 3 \\
\hline 10 & 62 & $\mathrm{~F}$ & 167 & 80 & III & 55 & 35 & 53 & 24 & 21 & 3 \\
\hline 11 & 69 & $\mathrm{~F}$ & 170 & 65 & III & 55 & 34 & 39 & 17 & 28 & 4 \\
\hline 12 & 68 & M & 183 & 90 & III & 55 & 33 & 41 & 21 & 23 & 4 \\
\hline 13 & 33 & $\mathrm{~F}$ & 172 & 58 & II & 55 & 30 & 40 & 22 & 17 & 4 \\
\hline Mean $\pm \mathrm{SD}$ & $60 \pm 13$ & & $171 \pm 10$ & $80 \pm 14$ & & & $33 \pm 5$ & $39 \pm 8.9$ & $20 \pm 3$ & $18 \pm 5$ & \\
\hline Range & $33-73$ & & $155-186$ & $58-98$ & & & $26-45$ & $28-57$ & $15-27$ & $11-28$ & \\
\hline
\end{tabular}

$M V$, Mitral valve; $N Y H A$, New York Heart Association functional class; $L V E F$, Left ventricular ejection fraction; $A P$, anteroposterior; $M L$, mediolateral; $M R$, mitral regurgitation; $L V E S D$, left ventricular end-systolic diameter; $L V E D D$, left ventricular end-diastolic diameter; $L A$, left atrial; $F$, female; $M$, male. 

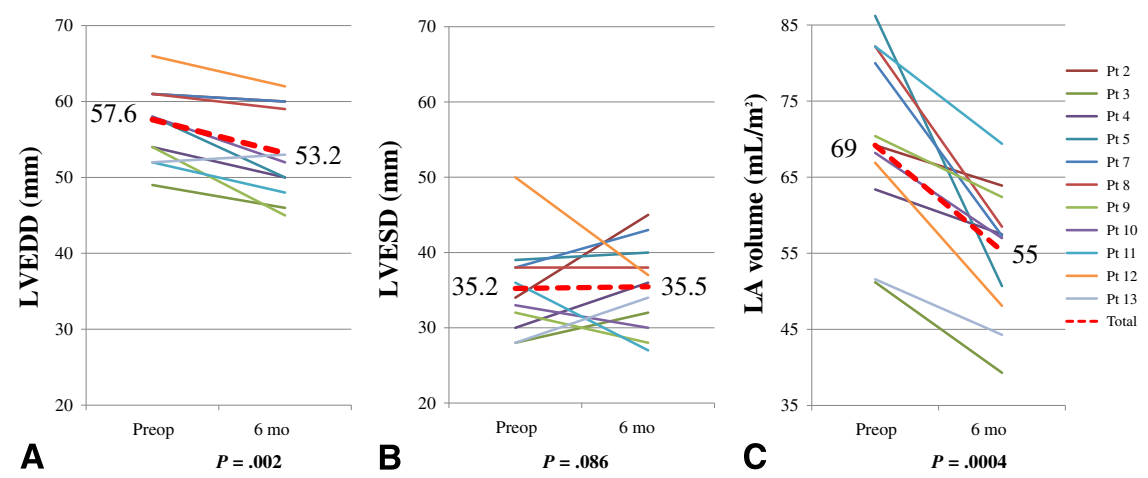

FIGURE 2. Reverse remodeling at 6 months' follow-up. A, Average left ventricular end-diastolic diameter (LVEDD) has reduced from 57.6 to 53.2 mm $(P=.002)$. B, Average left ventricular end-systolic diameter $(L V E S D)$ has increased nonsignificantly, from 35.2 to $35.5 \mathrm{~mm}(P=.86)$. C, Average indexed left atrial $(L A)$ volume has reduced from 69 to $55 \mathrm{~mL} / \mathrm{m}^{2}(P=.0004)$. Pt, Patient; Preop, preoperative.

white lights; if the leaflet is grasped only partially, there will be just 1,2 , or 3 white lights. The suture is deployed only if the leaflet is grasped with full depth of the jaws. The diameter of the instrument entering the LV is $8 \mathrm{~mm}$ (24F).

\section{NeoChord Procedure}

The neochord implantation procedure was performed with the patient under general anesthesia in ordinary cardiac surgery operating room. TEE was used for guidance. Intraoperative blood salvage was used in all cases. Access to the LV was achieved through a left lateral thoracotomy in the fifth intercostal space (4-5 cm incision). Two standard purse-string sutures were placed 2 to $4 \mathrm{~cm}$ posterolateral from the apex. A safe LV access site was obtained by probing the LV with a blunt probe or finger and viewing the proximity of the potential site to the papillary muscle. After ventriculotomy, a NeoChord DS1000 device loaded with single CV-4 suture (Gore-Tex; W. L. Gore \& Associates, Inc, Flagstaff, Ariz) was inserted in the LV, and 2- and 3-dimensional TEE used to navigate the instrument to the flailing segment of the posterior mitral valve leaflet.
Although advancement of the distal tip could be impeded by the native chordae, this was resolved with simple retraction of the device. Contact with the native chordae was minimized by slowly advancing the device while frequently observing the trajectory of the device in the long- and short-axis views.

The jaws of the device were opened, and the flailing segment was captured. Effective leaflet capture was confirmed by the 4 fiber-optic monitor lights changing from red to white. Once a neochord was deployed, the device was removed from the heart. Optimal placement of each neochord was evaluated by placing the neochord under tension and observing significant contribution to MR reduction. If the placement was deemed inappropriate, a retrieval suture was used to remove the deployed suture. The column for neochords attempted in Table 1 shows how many attempts were made to implant neochords in each patient. Neochord retrieval was accomplished by placing a polypropylene (Prolene; Ethicon, Inc, Somerville, NJ) suture through the loop of the neochord. As the hitch was advanced into position on the leaflet, the Prolene suture was advanced with the hitch. Retrieval was completed by holding both free ends of the Prolene suture while retracting the Prolene suture and expanded

TABLE 1. Continued

\begin{tabular}{|c|c|c|c|c|c|c|c|c|c|c|}
\hline \multicolumn{3}{|c|}{ Baseline } & \multicolumn{4}{|c|}{ Operative } & \multicolumn{4}{|c|}{ Follow up (6 mo) } \\
\hline \multirow{2}{*}{$\begin{array}{c}\text { LVESD } \\
(\mathrm{mm}) \\
\end{array}$} & \multirow{2}{*}{$\begin{array}{c}\text { LVEDD } \\
(\mathbf{m m})\end{array}$} & \multirow{2}{*}{$\begin{array}{c}\text { LA volume } \\
\text { index }\left(\mathrm{mL} / \mathrm{m}^{2}\right)\end{array}$} & \multirow{2}{*}{$\begin{array}{c}\text { Operative } \\
\text { duration (min) }\end{array}$} & \multirow{2}{*}{$\begin{array}{c}\text { Intraoperative } \\
\text { MR post } \\
\text { procedure }\end{array}$} & \multicolumn{2}{|c|}{ Neochords } & \multirow[b]{2}{*}{ MR grade } & \multirow{2}{*}{$\begin{array}{c}\text { LVESD } \\
(\mathrm{mm})\end{array}$} & \multirow{2}{*}{$\begin{array}{l}\text { LVEDD } \\
(\mathbf{m m})\end{array}$} & \multirow{2}{*}{$\begin{array}{c}\text { LA } \\
\text { measurements } \\
(\mathrm{mm})\end{array}$} \\
\hline & & & & & Attempted & Left & & & & \\
\hline 35 & 61 & 82 & \multicolumn{8}{|c|}{ Converted to standard care } \\
\hline 34 & 61 & 69 & 90 & 0 & 3 & 2 & 1 & 45 & 60 & 64 \\
\hline 28 & 49 & 51 & 105 & Trivial & 4 & 2 & 1 & 32 & 46 & 39 \\
\hline 30 & 54 & 63 & 100 & Trivial & 3 & 3 & 1 & 36 & 50 & 58 \\
\hline 39 & 58 & 86 & 120 & 0 & 4 & 2 & 2 & 40 & 50 & 51 \\
\hline 37 & 62 & 47 & 105 & Trivial & 2 & 2 & \multicolumn{4}{|c|}{ Converted to standard care } \\
\hline 38 & 61 & 80 & 115 & Trivial & 3 & 3 & 0 & 43 & 60 & 57 \\
\hline 38 & 61 & 82 & 150 & 1 & 5 & 3 & 2 & 38 & 59 & 59 \\
\hline 32 & 54 & 70 & 105 & Trivial & 2 & 2 & 2 & 28 & 45 & 62 \\
\hline 33 & 58 & 68 & 80 & Trivial & 2 & 2 & 1 & 30 & 52 & 57 \\
\hline 36 & 52 & 82 & 125 & Trivial & 4 & 3 & 0 & 27 & 48 & 69 \\
\hline 50 & 66 & 67 & 120 & Trivial & 5 & 4 & 2 & 37 & 62 & 48 \\
\hline 28 & 52 & 52 & 145 & 1 & 5 & 4 & 0 & 34 & 53 & 44 \\
\hline $35 \pm 6$ & $58 \pm 5$ & $69 \pm 13$ & $113 \pm 21$ & & $3.6 \pm 1.2$ & $2.7 \pm 0.8$ & & $35 \pm 6$ & $53 \pm 6.1$ & $55 \pm 9$ \\
\hline $28-50$ & $52-66$ & $47-86$ & $80-150$ & & $2-5$ & $2-4$ & & $27-45$ & $45-62$ & $39-69$ \\
\hline
\end{tabular}


polytetrafluoroethylene neochord from the leaflet. If MR was effectively reduced under light tension of the suture, the neochordal position was considered to be good and the neochord left in mitral valve leaflet (Table 1 shows how many neochords were left in place after procedure). In addition, a short-axis view was used to visualize the deployed neochords to determine desired position on the P1, P2, or P3 scallop. Deployed neochords were anchored to the epicardium by passing the sutures back through the LV wall and then suturing to the epicardium over a pledget adjacent to the ventriculotomy with a standard surgical knot. Tension and securing of neochords was controlled by TEE to achieve maximal competence of the mitral valve.

All patients have completed study follow-up visits before discharge and at 30 days and 6 months after the procedure, with 1- and 2-year follow-up ongoing.

\section{RESULTS}

Acute procedure success was achieved in $92 \%$ of the patients (12/13). Intraoperatively, 11 patients had less than trivial MR (84\%) and 2 patients had 1+ MR (16\%). Our first patient was converted to conventional mitral valve repair due to failure to effectively deploy neochords. Intraoperative conversion to standard open mitral valve repair was successfully completed in this patient. Leaflet damage could be seen during conventional mitral valve repair. In this case, we can only speculate that fragile leaflet tissue contributed to the inability to retain deployed neochords. One patient with 2 neochords implanted has developed recurrent MR at 30 day follow-up. In this patient prolapsing segment was narrow, recurrence of MR in this patient has developed due to dehiscence of 1 of the 2 deployed neochords.

Eleven remaining patients at 6 months' follow-up had MR of $2+$ or less. Three patients $(23 \%$ of all patients with attempted treatment) had MR grade 0,4 patients $(31 \%)$ had MR of grade 1 , and the other 4 patients $(31 \%)$ had MR of grade 2 at the 6-month follow-up time point. MR of $2+$ or less was acceptable per protocol, and no neochordal dehiscence was observed in these patients. Of the 12 patients who had intraoperative success, $6(50 \%)$ had 2 neochords implanted, $4(33 \%)$ had 3 neochords implanted, and $2(17 \%)$ had 4 neochords implanted.

At 6 months of follow-up, as would be expected, signs of $\mathrm{LV}$ and left atrial reverse remodeling were observed (Figure 2). Average LV end-diastolic diameter was reduced from $57.6 \mathrm{~mm}$ preoperatively to $53.2 \mathrm{~mm}$ postoperatively (reduction of $6 \%, P=.002$ ). Average LV end-systolic diameter was slightly but nonsignificantly increased from 35.2 to $35.5 \mathrm{~mm}$ (increase of $1 \%, P=.86$ ). Average indexed left atrial volume was reduced from 69 to $55 \mathrm{~mL} / \mathrm{m}^{2}$ (reduction of $20 \%, P=.0004$ ). Intraoperative and postoperative patient data are listed in Table 1.

Average NeoChord procedure duration time was 113 minutes (range, 80-150 minutes). Typical neochord deployment time was less than 5 minutes per chord, with tensioning and anchoring requiring about 10 minutes per chord.
Other than the conversion to standard care, there were no major adverse events related to the transapical implantation of neochords, and there were no other clinical events or complications noted through the 6-month follow-up period.

\section{DISCUSSION}

Transapical beating-heart implantation of neochords is a novel surgical procedure for performing mitral valve repair in patients with severe MR. The goal of the procedure is to decrease the invasiveness of mitral valve repair procedures and to avoid the risks of cardiopulmonary bypass and aortic crossclamping.

The procedure of transapical implantation of neochords has evolved during the TACT study. One of the procedural refinements was to move the LV access and neochordal anchoring site 2 to $4 \mathrm{~cm}$ posterolateral from the apex. This difference from initial recommendations ${ }^{9}$ is based on recent publications ${ }^{10}$ suggesting that the load on neochords can be reduced by deploying shorter neochords with an anchoring vector similar to that of native chordae. Also, after late recurrence of MR in 1 of our patients, we focused on deploying more neochords to reinforce mitral valve competence. The TACT study does include early patients (in other study sites) who have maintained a $1+$ or trace MR grade beyond 2 years with neochords anchored to the LV apex; however, our early experience suggests that the posterolateral access and anchoring site and the deployment of multiple neochords together improve patient outcomes. Selection of patient remains very important. One of our patients with a narrow prolapsing segment had early recurrence of MR, and we therefore believe that cases of narrow prolapse are more challenging and should wait more experience with the device.

In our patient group, transapical neochord implantation under beating-heart conditions was feasible, could be performed safely, and resulted in a relatively short procedure time. Additional questions remain regarding this promising repair technique. The long-term durability of the NeoChord procedure remains to be proved. The target population and pathology for use of this device has to be found. Is it going to be patients who are described as "too healthy" for conventional procedures or patients described as "too sick" for surgery? Or both?

We are encouraged by our results in treating low-risk patients with severe MR who are in need of a surgical intervention. A more pressing clinical need is the treatment of patients with a higher surgical risk profile. A beatingheart off-pump procedure may offer a less-invasive approach for treating patients for whom surgical treatment is complicated by multiple comorbidities. With the conclusion of the TACT Study and CE Mark, the TACT Registry (clinicaltrials.gov ID: NCT01784055) has been initiated in Europe. With more and different patients, the TACT 
registry will help to clarify the surgical applications and long-term results of this procedure.

\section{References}

1. Rankin JS, Gaca JG, Brunsting LA III, Daneshmand MA, Milano CA, Glower DD, et al. Increasing mitral valve repair rates with nonresectional techniques. Innovations (Phila). 2011;6:209-20

2. Johnston DR, Gillinov AM, Blackstone EH, Griffin B, Stewart W, Sabik JF III, et al. Surgical repair of posterior mitral valve prolapse: implications for guidelines and percutaneous repair. Ann Thorac Surg. 2010;89:1385-94.

3. Mihaljevic T, Blackstone EH, Lytle BW. Folding valvuloplasty without leaflet resection: simplified method for mitral valve repair. Ann Thorac Surg. 2006; 82:e46-8.

4. Gammie JS, Sheng S, Griffith BP, Peterson ED, Rankin JS, O'Brien SM, et al. Trends in mitral valve surgery in the United States: Results from The Society of Thoracic Surgeons Adult Cardiac Database. Ann Thorac Surg. 2009;87:1431-9.

5. Castillo JG, Anyanwu AC, Fuster V, Adams DH. A near 100\% repair rate for mitral valve prolapse is achievable in a reference center: implications for future guidelines. J Thorac Cardiovasc Surg. 2012;144:308-12.

6. Enriquez-Sarano M, Sundt TM III. Early surgery is recommended for mitral regurgitation. Circulation. 2010;121:804-11; discussion 812

7. Stevens LM, Rodriguez E, Lehr EJ, Kindell LC, Nifong LW, Ferguson TB, et al. Impact of timing and surgical approach on outcomes after mitral valve regurgitation operations. Ann Thorac Surg. 2012;93:1462-8.

8. Suri RM, Schaff HV, Dearani JA, Sundt TM, Daly RC, Mullany CJ, et al. Recovery of left ventricular function after surgical correction of mitral regurgitation caused by leaflet prolapse. J Thorac Cardiovasc Surg. 2009;137:1071-6.

9. Seeburger J, Winkfein M, Hoebartner M, Noack T, Kiefer P, Vollroth M, et al. Transapical neochord implantation. MMCTS 2011; http://dx.doi.org/10.1510/ mmcts.2010.004606.

10. Weber A, Hurni S, Vandenberghe S, Wahl A, Aymard T, Vogel R, et al. Ideal site for ventricular anchoring of artificial chordae in mitral regurgitation. $J$ Thorac Cardiovasc Surg. 2012;143(4 Suppl):S78-81.

\section{Discussion}

Dr Georg Lutter (Kiel, Germany). Congratulations on your latest result. I want to ask you whether you measured the length of your neochords between your apex and your posterior leaflet. Did you put it more toward the posterolateral side, meaning that this is more stable than seen in the patients in whom you put your neochords directly towards the apex, and therefore did you measure the length over time between the apex and the posterior leaflet? We would like to know how to get stable results referring to your neochords. What did you observe in your successful cases with your repair of your posterior leaflet?

Dr Speziali. Proper tensioning of the neochords is a critical element of this procedure, and intraoperatively we fill the heart and we tension the neochords under direct visualization. We pull the neochords enough to make the prolapse go away. There is a difference between the apex and the posterolateral segment of the LV regarding the distance with the mitral annular plane: the apex distance to the mitral plane is fixed, but the posterolateral segment moves in and out during diastole and systole, and I think that also reduces the snap on the neochords when the valve closes. So it is not just a matter of length, it is a matter of force applied to the chord that gets transmitted to the chord-leaflet interface.

It is difficult to figure out in a few patients exactly what the major determinant of neochordal tension and durability is, also from an engineering and geometric standpoint.

Dr Lutter. Could you also imagine going with your NeoChord device into one of the papillary muscles and then afterward going into your posterior leaflet, $\mathrm{P} 2$, and fixing it over there?

Dr Speziali. I don't want to stick that instrument through the papillary muscle, because it is a lot of muscle you'd have to go through. Possibly when we come out of the apex, however, we can go back with a French eye needle and then reach the head of the papillary muscle and then out again. It has been done in a few of these cases.

Dr Thierry Mesana (Ottawa, Ontario, Canada). Congratulations. This is a very nice device. I have 2 technical questions. Maybe one you can answer; the other one you have to wait a few years to answer.

First, can you really address P1 or P3 and not only P2? Most of these posterior leaflet prolapses, or maybe half of them, are not simple P2 prolapse. Second, do you think that by having your device positioned in the apex and having to go through a thoracotomy, you can induce adhesions and transformation of the apex and then gradually with time have some fibrotic formation here? They are going to change the anatomy of the chord itself implanted in the apex. But it's a nice study.

Dr Speziali. For the second question, we put a purse-string suture with pledgets as for a transcatheter aortic valve implantation, and that has not been a problem so far. The sutures are actually anchored to the pledgets, not to the muscle itself. So I think it's unlikely that the pledget migrates or that changes the geometry.

What was the first question?

Dr Williams. Whether you can treat P1 or P3, anterior leaflet.

Dr Speziali. The inclusion criteria didn't specify P2.

Dr Williams. Do you think you can with this device? Do you think you can treat P1 and P3?

Dr Speziali. Yes, I meant that we have done this. Both P1 and P3 were treated in this series. 